\title{
Awareness, Uptake and factors associated with NHIF uptake in Western Kenya. A case of 4 counties - Busia, Trans Nzoia, Vihiga and Siaya
}

Grace Wandia Mwaura ( $\square$ wandiahgrace@gmail.com )

Moi University School of Medicine https://orcid.org/0000-0003-2738-4406

Jemima H. Kamano

Moi University School of Medicine

Ann W. Mwangi

Moi University School of Medicine

Lilian Lusimbo

Academic Model Providing Access to Healthcare: AMPATH Kenya

Richard Mugo

Academic Model Providing Access to Healthcare: AMPATH Kenya

Kenneth Too

Academic Model Providing Access to Healthcare: AMPATH Kenya

Thomas Andale

Moi Teaching and Referral Hospital

Peter Itsura

Moi University

Joseph Kibachio

World Health Organization Kenya

Gladwell Gathecha

Kenya MOH: Kenya Ministry of Health

Wilson Aruasa

Moi Teaching and Referral Hospital

\section{Research}

Keywords: National Hospital Insurance Fund, Awareness, Uptake, Universal Health Coverage, Western Kenya

Posted Date: May 5th, 2021

DOl: https://doi.org/10.21203/rs.3.rs-479001/v1 
License: (c) (i) This work is licensed under a Creative Commons Attribution 4.0 International License. Read Full License 


\section{Abstract \\ Background}

Kenya is in the process of implementing universal health care whose success and sustainability will be determined by its funding mechanism and by uptake of National Hospital Insurance Fund (NHIF) by its populace. Unfortunately, NHIF enrollment is currently voluntary hence geared to those in formal employment who represent only $16.4 \%$ of the population. To improve the voluntary uptake of the scheme, it is important to have increased awareness as well as implement strategies that address factors that currently affect NHIF uptake.

\section{Methods}

This was a cross sectional community-based survey conducted in Busia, Trans Nzoia, Vihiga and Siaya counties between October and December 2018. It utilized multistage stratified sampling technique. Interviewer assisted questionnaires were used to collect socio-demographic, socio-economic, NonCommunicable Diseases (NCD) knowledge, NHIF awareness and uptake data. Descriptive statistical analysis and multiple logistic regression were conducted using STATA version 15.

\section{Results}

Out of a representative sample of 3597 participants interviewed, NHIF awareness was noted to be $81.5 \%$, with low uptake in the four counties ranging between $21-25 \%$. Being older than 69 years, having a low level of education and income status as well as lower health risk were significantly associated with low rates of NHIF uptake.

\section{Conclusion}

Despite high rates of NHIF awareness noted in this study, there is still very low uptake to this scheme in rural western Kenya especially among those with low socioeconomic status and risk of chronic illnesses. There is need for further qualitative studies to explore contextual factors affecting NHIF uptake.

\section{Introduction}

Social health insurance $(\mathrm{SHI})$ is a key strategy for achieving universal health coverage through provision of financial protection. It is actualized by having populations mandated to enroll and remit premiums for health insurance (1). The funds are pooled and used to offer health services to enrollees when they are unwell. By pooling funds, a SHI program allows a country to care for its citizens equitably. Different countries journey differently in the implementation of SHI ranging from initial mandatory enrollment for 
those in formal employment, with progressive inclusion of those in the informal sector, to allow eventually coverage of the whole population with subsidization of certain disadvantaged groups (2).

Most Low- and middle-income-countries (LMICs) such as Kenya; have previously relied on tax revenues to partially finance healthcare, and out of pocket spending to meet the balance. This has led to under financing of healthcare, over-reliance on donor funding and largely inequitable health services provision. Majority of health expenditure in LMICs is borne through out-of-pocket payment leading to an inequitable and inefficient health financing (3). Out of pocket expenditure on health care absorbs household's financial resources hence increasing the incidence of catastrophic expenditure (4). Global estimates indicate that every year, nearly 150 million people experience catastrophic health expenditure (5). Universal Health Coverage (UHC) is one of the strategies by the World Health Organisation (WHO) for responding to catastrophic healthcare expenditure (6).

To address this inequity, there has been a move to SHI aimed at UHC. Many African countries introduced Community based health insurance $(\mathrm{CBHI})$ which are voluntary and organized within community units. Unfortunately systematic review assessing rates of enrollment in $\mathrm{CBHI}$ in Africa found that only 2 million people out of the total population of 900 million (0.2\%) were enrolled in CBHIs (7).

Uptake of SHI in different African countries has been variable with a pilot SHI project in Ethiopia having reached $48 \%$ enrollment within 1 year of initiation, while a study in Nigeria revealed much poorer uptake at $4.5 \%(8)$.

The initial step towards UHC in Kenya was the introduction of mandatory health insurance enrollment into the National Hospital Insurance Fund (NHIF) for those in formal employment and voluntary health insurance for those in the informal sector. The country then embarked on subsidized enrollment for all elderly and disabled persons leading to an increase in the overall NHIF uptake (7.7mil 2017/2018 to $8.5 \mathrm{mil} 2018 / 2019)$. These efforts have also born fruit in growth of the informal sector membership by $12.7 \%$ compared to $8.7 \%$ in the formal sector in $2018 / 2019(9,10)$.

Despite these gains the country's enrollment rates have remained skewed to the formal sector with NHIF uptake in Nairobi slums described to be as low as $<10 \%$ (11). Kenya is in the process of implementing universal health care whose sustainability will be determined by its funding mechanism and by the growth of NHIF. Unfortunately, NHIF is currently only mandatory for those in formal employment yet a staggering $83.4 \%$ of the productive population works in the informal sector(12). For voluntary uptake of NHIF to reach desired levels, awareness of the existence of the scheme, its cost, and its benefits in the population is imperative. Additionally, it is critical that there is a good understanding of factors affecting NHIF uptake so that these can be adequately addressed. There are several factors that have been shown to affect the uptake of insurance in many countries.

\section{Income}


Income is the most important determinant of social and economic health, it also determines overall living conditions, psychological functioning and influences health related behavior such as food security, housing, participation in cultural activities and all these leads to effects on one's health and lessen the ability for one to live a fulfilling life (13). Household income in both developing and developed countries determines the amount of health insurance to be purchased. One of the major barriers to access health services is financial constraints. Approximately 1.3 billion worldwide are poor and cannot afford to access health services(14). The activities in the informal sector are linked with inadequate income maintenance and income generating activities which in turn leads to high level of poverty, and poor accessibility to healthcare services.

\section{Education Level}

According to studies by(15) suggested that health Insurance is a complex product to its consumers. People with little knowledge and understanding on universal health care have low use of health insurance.(16) For health insurance uptake to improve then people should be well informed on the same hence literacy in the health systems of a country should be undertaken.

\section{Health status}

Health status determines the uptake of health Insurance for example when one member of the household is chronically ill the family will opt for a health insurance based on probability of future health events or the number of children that one has(17) In Rwanda, one study indicated that large household of more than five members of the family had a greater probability of enrolling with health insurance(18).

Other demographic factors that have been associated with health insurance uptake in some studies include, age, gender and marital status.

Some studies have shown that high age groups had a higher probability of enrolling into a health insurance than the lower age group because the aged were able to understand their health risks. (19)The contrary has also been described whereby the older population have less income and hence are unable to take up health insurance(20)

The association of gender with health insurance uptake has been very variable with some studies showing that women purchase health Insurance more frequently than men, $((11,21))$ while others showed the contrary where women do not make decisions on health insurance enrollment but men do.

For marital status, some of the studies have shown that those who are married are likely to enroll in NHIF because of the financial support they have from their partners and for singles register low enrollment on NHIF.(23)

There is a need to improve health service delivery and financing yet there is paucity of data on NHIF awareness uptake and factors affecting its uptake in western Kenya. We set out to fill this gap. 


\section{Study setting}

Academic Model Providing Access To Healthcare (AMPATH) was established in Kenya in 2001, and has developed an HIV care system in Western Kenya that serves over 100,000 patients.(18) Building upon this foundation, AMPATH has expanded its clinical scope of work in several counties in western Kenya, to address comprehensive primary care, including Non communicable diseases.(19)This study was conducted in two AMPATH supported counties Busia and Trans Nzoia, and two non-AMPATH supported counties, Vihiga and siaya.

\section{Study design}

A cross-sectional survey was conducted. Multistage stratified sampling technique was used.

Stratification was done by link facility, Community unit (CU), village, age and gender. The sampling frame was based on the list of facilities from the country's master Facility list, their catchment CUs, and their villages.

The cross-sectional survey was carried out from October2018 to December 2018 by 10 research assistants. The assistants underwent a 5-day study specific training conducted by the research team. The training involved understanding the content of the questionnaires, the consenting process and data transmission. As part of the training, they pre-tested the tools in Turbo sub-county, Uasin Gishu County.

Prior to data collection reconnaissance meetings were held in all the four counties to introduce the study and the team to the County Health officials as well as the facilities that were involved in the study.

Community health volunteers, Chiefs, and village elders mobilized the community members for the study prior to the data collection process. The interviews were conducted in the homesteads at the convenience of the participants.

\section{Study population}

The study targeted all adults aged above 18 years who gave informed consent and were residing within the four counties. We excluded persons who could not withstand a one hour interview due to illness or very advanced old age $>90$ years.

\section{Study procedure}

An interviewer assisted questionnaire was used to collect socio-demographic, socio-economic, NCD knowledge, NHIF awareness and uptake data. The questionnaire was developed in both English and Kiswahili language allowing the research assistant to use either depending on the interviewee's preference.

\section{Data management and Analysis}


Data was collected using an electronic record system and transferred to a REDCap system. Data were cleaned and exported to STATA version 15 for analysis that involved descriptive statistics to describe the NHIF uptake. Bivariate analysis was carried out using Chi square test to assess the association between socio demographic characteristics and NHIF awareness and uptake. Derived variable: Health risk. One was considered high risk if they had been told by a doctor that they suffered from at least one of the following ailments, Diabetes, hypertension, stroke, Myocardial infarction, poor blood pressure, heart failure, kidney disease, following cancers; cervical, esophagus, breast, prostate or any other ailment. Low risk participants were those who had none of the mentioned diseases.

Multivariate logistic regression model to adjust for confounding was used to identify cross sectional predictive factors associated with NHIF uptake and awareness. In all analysis a p-value less than 0.05 was considered to be significant.

\section{Ethical considerations}

The proposal was approved by the MTRH/Moi University Institutional Research and Ethics Committee (approval number 0002090), and National Commission for Science technology and Innovation (NACOSTI) (approval number NACOSTI/P/18/74238/24329) and the 4 County Health Management Teams (CHMTs). A written consent was obtained from all participants enrolled in the study who accepted to participate. Illiterate eligible women had their thumb prints taken and the process was witnessed by an independent adult. The IREC guidelines on confidentiality on research among vulnerable groups were followed. Data confidentiality was ensured by password protecting the computer.

\section{Results}

A total of 3597 people were interviewed in the four counties, of whom $51.6 \%$ were women. The average age of the participants was $43.85( \pm 15.92)$ years with the highest proportion being those aged $30-44$ years. Secondary level of education and above was noted in $36.7 \%$ of participants, while $23.3 \%$ had completed primary education and only $8.1 \%$ had no formal education (Table 1 ). 
Table 1

Participant characteristics across counties

\begin{tabular}{|c|c|c|c|c|c|}
\hline \multirow[t]{2}{*}{ Variable } & Busia & Siaya & \multirow{2}{*}{$\begin{array}{l}\text { Trans-Nzoia ( } \mathrm{N}= \\
899)\end{array}$} & \multirow{2}{*}{$\begin{array}{l}\text { Vihiga ( }= \\
901)\end{array}$} & \multirow{2}{*}{$\begin{array}{l}\text { Total }(\mathrm{N}= \\
\text { 3597) }\end{array}$} \\
\hline & $(\mathrm{N}=901)$ & $(N=896)$ & & & \\
\hline \multicolumn{6}{|l|}{ Gender } \\
\hline Men & $\begin{array}{l}447 \\
(49.6 \%)\end{array}$ & $\begin{array}{l}456 \\
(50.9 \%)\end{array}$ & 441 (49.1\%) & 398 (44.2\%) & 1742 (48.4\%) \\
\hline Women & $\begin{array}{l}454 \\
(50.4 \%)\end{array}$ & $\begin{array}{l}440 \\
(49.1 \%)\end{array}$ & $458(50.9 \%)$ & $503(55.8 \%)$ & $1855(51.6 \%)$ \\
\hline \multicolumn{6}{|l|}{ Age in years } \\
\hline Mean (SD) & $\begin{array}{l}43.26 \\
(16.56)\end{array}$ & $\begin{array}{l}40.75 \\
(14.79)\end{array}$ & 47.30 (16.89) & $44.11(14.62)$ & 43.86 (15.92) \\
\hline \multicolumn{6}{|l|}{ Age group } \\
\hline $18-29$ & $\begin{array}{l}221 \\
(24.5 \%)\end{array}$ & $\begin{array}{l}264 \\
(29.5 \%)\end{array}$ & 170 (18.9\%) & $190(21.1 \%)$ & 845 (23.5\%) \\
\hline $30-44$ & $\begin{array}{l}299 \\
(33.2 \%)\end{array}$ & $\begin{array}{l}281 \\
(31.4 \%)\end{array}$ & $258(28.7 \%)$ & $258(28.6 \%)$ & 1096 (30.5\%) \\
\hline $45-59$ & $\begin{array}{l}225 \\
(25.0 \%)\end{array}$ & $\begin{array}{l}225 \\
(25.1 \%)\end{array}$ & $255(28.4 \%)$ & $278(30.9 \%)$ & $983(27.3 \%)$ \\
\hline $60-69$ & $91(10.1 \%)$ & $\begin{array}{l}124 \\
(13.8 \%)\end{array}$ & $116(12.9 \%)$ & $175(19.4 \%)$ & $506(14.1 \%)$ \\
\hline$\geq 70$ & $65(7.2 \%)$ & $2(0.2 \%)$ & $100(11.1 \%)$ & $0(0.0 \%)$ & $167(4.6 \%)$ \\
\hline \multicolumn{6}{|l|}{ Education } \\
\hline No formal & $80(8.9 \%)$ & 47 (5.2\%) & $111(12.3 \%)$ & $52(5.8 \%)$ & 290 (8.1\%) \\
\hline $\begin{array}{l}\text { Incomplete } \\
\text { Primary }\end{array}$ & $\begin{array}{l}317 \\
(35.2 \%)\end{array}$ & $\begin{array}{l}259 \\
(28.9 \%)\end{array}$ & $351(39.0 \%)$ & $223(24.8 \%)$ & $1150(32.0 \%)$ \\
\hline $\begin{array}{l}\text { Complete } \\
\text { Primary }\end{array}$ & $\begin{array}{l}148 \\
(16.4 \%)\end{array}$ & $\begin{array}{l}278 \\
(31.0 \%)\end{array}$ & $165(18.4 \%)$ & 247 (27.4\%) & $838(23.3 \%)$ \\
\hline $\begin{array}{l}\text { Secondary \& } \\
\text { above }\end{array}$ & $\begin{array}{l}356 \\
(39.5 \%)\end{array}$ & $\begin{array}{l}312 \\
(34.8 \%)\end{array}$ & $272(30.3 \%)$ & $379(42.1 \%)$ & 1319 (36.7\%) \\
\hline
\end{tabular}

This study reports a high (81.5\%) overall NHIF awareness among the study participants with the highest level of awareness seen among participants aged 30-44years. Notably, the levels of awareness declined with advancement in age. Awareness levels were also higher among those who were married and with a higher level of education. Despite the high level of NHIF awareness recorded, its uptake was poor across the four counties ranging between $21 \%$ and $25 \%$. There was a statistically significant association between age, marital status, income, level of education and health risk with NHIF uptake. However, there 
was neither a statistically significant association between NHIF uptake and gender, nor a significant difference in the level of uptake by county. The uptake of NHIF increased with advancing age, from 1829 years $(12.7 \%)$ to 70 years and above (28.2\%). The uptake of NHIF was significantly higher among those with increasing level of education and also having a high health risk (32.4\%) compared to those with low health risks at $19.4 \%$ (Table 2). 
Table 2

Prevalence of NHIF awareness across sex, age group, education and counties

\begin{tabular}{|c|c|c|c|c|c|c|}
\hline \multirow[t]{2}{*}{ Variable } & \multicolumn{3}{|l|}{ Awareness } & \multicolumn{3}{|l|}{ Uptake } \\
\hline & $\begin{array}{l}\text { Aware }(\mathrm{N}= \\
2900)\end{array}$ & $\begin{array}{l}\text { Unaware }(\mathrm{N}= \\
657)\end{array}$ & $\begin{array}{l}p \\
\text { value }\end{array}$ & $\begin{array}{l}\text { Yes }(N= \\
643)\end{array}$ & $\begin{array}{l}\text { No }(\mathrm{N}= \\
2257)\end{array}$ & $\begin{array}{l}p \\
\text { value }\end{array}$ \\
\hline Gender & & & 0.005 & & & 0.77 \\
\hline Men & $1442(83.4)$ & $287(16.6)$ & & $323(22.4)$ & $\begin{array}{l}1119 \\
(77.6)\end{array}$ & \\
\hline Women & $1458(79.8)$ & $370(20.2)$ & & 320 (21.9) & $\begin{array}{l}1138 \\
(78.1)\end{array}$ & \\
\hline Age Group & & & $\begin{array}{l}<.001 \\
0.00\end{array}$ & & & $\begin{array}{l}<.001 \\
0.00\end{array}$ \\
\hline $18-29$ & $686(82)$ & $151(18)$ & & $87(12.7)$ & 599 (87.3) & \\
\hline $30-44$ & $938(86.3)$ & 149 (13.7) & & $217(23.1)$ & 721 (76.9) & \\
\hline $45-59$ & 795 (82) & $175(18)$ & & $200(25.2)$ & $595(74.8)$ & \\
\hline $60-69$ & 371 (74.3) & $128(25.7)$ & & $108(29.1)$ & 263 (70.9) & \\
\hline$\geq 70$ & $110(67.1)$ & $54(32.9)$ & & $31(28.2)$ & 79 (71.8) & \\
\hline Marital Status & & & $\begin{array}{l}< \\
0.001\end{array}$ & & & $\begin{array}{l}<.001 \\
0.001\end{array}$ \\
\hline Single & $666(74.9)$ & $223(25.1)$ & & $113(17)$ & $553(83)$ & \\
\hline Married & $2233(83.7)$ & $434(16.3)$ & & $530(75.7)$ & $170(24.3)$ & \\
\hline Income & & & $<.001$ & & & $\begin{array}{l}< \\
0.001\end{array}$ \\
\hline$<5,000$ & $390(66)$ & $201(34)$ & & $57(14.6)$ & $333(85.4)$ & \\
\hline $5,000-10,000$ & $197(77)$ & $59(23)$ & & $49(24.9)$ & $148(75.1)$ & \\
\hline$>10,000$ & $125(96.2)$ & $5(3.8)$ & & $50(40)$ & $75(60)$ & \\
\hline Education & & & $<.001$ & & & $\begin{array}{l}< \\
0.001\end{array}$ \\
\hline No formal & $152(53.3)$ & $133(46.7)$ & & $20(13.2)$ & $132(86.8)$ & \\
\hline $\begin{array}{l}\text { Incomplete } \\
\text { Primary }\end{array}$ & 849 (74.7) & $287(25.3)$ & & $105(12.4)$ & $744(87.6)$ & \\
\hline Complete Primary & 677 (81.5) & $154(18.5)$ & & $117(17.3)$ & $560(82.7)$ & \\
\hline $\begin{array}{l}\text { Secondary and } \\
\text { above }\end{array}$ & $1222(93.6)$ & $83(6.4)$ & & $401(32.8)$ & $821(67.2)$ & \\
\hline
\end{tabular}




\begin{tabular}{|c|c|c|c|c|c|c|}
\hline \multirow[t]{2}{*}{ Variable } & \multicolumn{3}{|l|}{ Awareness } & \multicolumn{3}{|l|}{ Uptake } \\
\hline & $\begin{array}{l}\text { Aware }(\mathrm{N}= \\
2900)\end{array}$ & $\begin{array}{l}\text { Unaware }(\mathrm{N}= \\
657)\end{array}$ & $\begin{array}{l}\mathrm{p} \\
\text { value }\end{array}$ & $\begin{array}{l}\text { Yes }(N= \\
643)\end{array}$ & $\begin{array}{l}\text { No }(\mathrm{N}= \\
2257)\end{array}$ & $\begin{array}{l}\text { p } \\
\text { value }\end{array}$ \\
\hline Health risk & & & 0.047 & & & $\dot{0} .001$ \\
\hline Low Risk & $2231(80.8)$ & $529(19.2)$ & & $433(70.8)$ & $179(29.2)$ & \\
\hline High Risk & 669 (83.9) & $128(16.1)$ & & $210(31.4)$ & 459 (68.6) & \\
\hline County & & & $\begin{array}{l}<.001 \\
0.001\end{array}$ & & & 0.251 \\
\hline Busia & 766 (89) & $95(11)$ & & $189(24.7)$ & 577 (75.3) & \\
\hline Siaya & $651(72.7)$ & 245 (27.3) & & $138(21.2)$ & $513(78.8)$ & \\
\hline Trans-Nzoia & 791 (88) & $108(12)$ & & $164(20.7)$ & $627(79.3)$ & \\
\hline Vihiga & $692(76.8)$ & $209(23.2)$ & & $540(78)$ & $152(22)$ & \\
\hline
\end{tabular}

The multivariate analysis demonstrated no significant association between NHIF awareness and age, gender and health risk. However, participants who were married were 1.6 times more likely to be aware of NHIF compared to single participants (AOR $=1.58,95 \% \mathrm{Cl}: 1.12,2.27)$. The level of awareness decreased significantly with decreasing income level. Notably participants with secondary level of education were 3 times more likely to have NHIF than those with complete primary education (AOR $=2.92 ; 95 \% \mathrm{Cl}: 1.88$, 4.59). There was no statistically significant association between level of uptake and gender, marital status, education level and county when education, income, age, marital status, health risk and county of origin were adjusted for. However the odds of uptake of NHIF increased with increasing age up to 69 years and then decreased for those aged 70 years and above. A statistically significant association was noted between income levels and NHIF uptake after adjustment $(p<0.05)$. Earning below Ksh. 5,000 per month was associated with a lower odds of paying NHIF, (AOR $=0.24,95 \% \mathrm{Cl}(0.14,0.41)$, for instance persons earning less than 5,000 were 4 times less likely to have an active NHIF cover compared to those earning more than Ksh 10,000 per month. Those earning between 5000 and 10000 were 2 times less likely to have NHIF compared to those earning more than 10,000 (AOR $=0.41,95 \% \mathrm{Cl}: 0.24,0.71)$. Those at high health risk were 3 times more likely to have NHIF than those at low health risk $(A O R=3.06,95 \% \mathrm{Cl}$ : $1.87,5.04)$ adjusting for other variables.

Controlling for other variables there was no difference in the odds of uptake of NHIF between persons having no formal education, $(\mathrm{AOR}=0.76,95 \% \mathrm{Cl}$ : $0.23,2.13)$, those with Incomplete education ( $\mathrm{AOR}=0.52$ $, 95 \% \mathrm{Cl}: 0.25,1.04)$ compared to those who have completed primary school education. However, there were increased odds ( $\mathrm{AOR}=2.34,95 \% \mathrm{Cl}: 1.41,3.96)$ of having an active NHIF cover among those who had completed secondary level of education or more compared to those with completed primary school education (Table 3). 
Table 3

Multiple Logistic regressions for factors associated with NHIF awareness and uptake.

\begin{tabular}{|c|c|c|c|c|c|c|}
\hline \multirow[t]{2}{*}{ Variable } & \multicolumn{3}{|c|}{ Awareness } & \multicolumn{3}{|c|}{ Uptake } \\
\hline & AOR & $95 \% \mathrm{Cl}$ & P-value & AOR & $95 \% \mathrm{Cl}$ & P-value \\
\hline \multicolumn{7}{|l|}{ Gender } \\
\hline Men & 1 & & & 1 & & \\
\hline Women & 1.14 & $(0.82,1.58)$ & 0.45 & 1.13 & $(0.75,1.71)$ & 0.57 \\
\hline \multicolumn{7}{|l|}{ Age Group } \\
\hline $18-29$ & 1 & & & 1 & & \\
\hline $30-44$ & 1.48 & $(0.93,2.36)$ & 0.1 & 3.16 & $(1.66,6.18)$ & 0 \\
\hline $45-59$ & 1.49 & $(0.93,2.39)$ & 0.1 & 4.95 & $(2.58,9.78)$ & 0 \\
\hline $60-69$ & 1.49 & $(0.87,2.59)$ & 0.15 & 7.03 & $(3.27,15.38)$ & 0 \\
\hline$\geq 70$ & 0.28 & $(0.08,0.97)$ & 0.05 & 4.39 & $(0.49,30.13)$ & 0.14 \\
\hline \multicolumn{7}{|l|}{ Marital Status } \\
\hline Single & 1 & & & 1 & & \\
\hline Married & 1.58 & $(1.12,2.27)$ & 0.01 & 0.92 & $(0.56,1.53)$ & 0.76 \\
\hline \multicolumn{7}{|l|}{ Income } \\
\hline$>10,000$ & 1 & & 0 & 1 & & \\
\hline $5,000-10,000$ & 0.16 & $(0.05,0.39)$ & 0 & 0.41 & $(0.24,0.71)$ & 0 \\
\hline$<5,000$ & 0.15 & $(0.05,0.35)$ & & 0.24 & $(0.14,0.41)$ & 0 \\
\hline \multicolumn{7}{|l|}{ Education } \\
\hline Complete Primary & 1 & & & 1 & & \\
\hline Incomplete Primary & 0.52 & $(0.35,0.78)$ & 0 & 0.52 & $(0.25,1.04)$ & 0.07 \\
\hline No formal & 0.15 & $(0.08,0.27)$ & 0 & 0.76 & $(0.23,2.13)$ & 0.61 \\
\hline Secondary and above & 2.92 & $(1.88,4.59)$ & 0 & 2.34 & $(1.41,3.96)$ & 0 \\
\hline \multicolumn{7}{|l|}{ Health risk } \\
\hline Low Risk & 1 & & & 1 & & \\
\hline High Risk & 1.57 & $(1.0,2.47)$ & 0.05 & 3.06 & $(1.87,5.04)$ & 0 \\
\hline \multicolumn{7}{|l|}{ County } \\
\hline Busia & 1 & & & 1 & & \\
\hline
\end{tabular}




\begin{tabular}{|lllllll|}
\hline Variable & \multicolumn{5}{l}{ Awareness } & \multicolumn{4}{l|}{ Uptake } \\
\cline { 2 - 7 } & AOR & $\mathbf{9 5 \%} \mathrm{Cl}$ & P-value & AOR & $\mathbf{9 5 \%} \mathrm{Cl}$ & P-value \\
\hline Siaya & 0.24 & $(0.11,0.48)$ & 0 & 0.64 & $(0.34,1.2)$ & 0.16 \\
\hline Trans-Nzoia & 0.43 & $(0.14,1.43)$ & 0.16 & 0.19 & $(0.02,0.88)$ & 0.06 \\
\hline Vihiga & 0.18 & $(0.08,0.35)$ & 0 & 0.68 & $(0.37,1.23)$ & 0.19 \\
\hline
\end{tabular}

\section{Discussion}

To the best of our knowledge this study is unique in that it is the first study on NHIF uptake and its determinants in Kenya to be done in a wide region including four different counties with a large number of participants. As such it included a very heterogeneous group of people with very good representation of both genders. Of note is the relatively young age of the interviewees which is representative of the population distribution of the four counties as per the

Kenya Population and housing census (KPHC) 2019 report .(24)

Not surprisingly the study found a relatively good level of NHIF awareness amongst participants across the four counties at an average of $81.4 \%$. This is lower than the $98 \%$ awareness reported by a study done in informal settlements in Kakamega in 2015. The Kakamega study enrolled fewer participants and a more homogenous group in that they were in informal settlements with a higher percentage of them being in some form of employment compared to our participants. Importantly, that study did dig deeper into the actual kind of knowledge participants had on NHIF and found that only $34 \%$ had the correct knowledge. It is therefore possible that despite the high rates of awareness we recorded, the actual knowledge held may not be correct.(23)

Key factors associated with increased awareness in this study on multivariate analysis were younger age groups, being married, higher income level and higher health risk. Previous studies showed that most people get NHIF information from the media and hence it's not surprising that younger persons were more aware (25). Additionally, those with higher health risks are often informed about NHIF in health facilities as part of planning for their long-term management. Unfortunately, the good level of NHIF awareness did not translate to high levels of uptake. This has been shown before in several studies. In Ghana, high awareness of their national health insurance scheme was found not to translate to uptake especially for the most vulnerable groups due to lack of social support. (26)

NHIF uptake in the four counties was similar, ranging from only $21-25 \%$. This is lower than the uptake rates described in Kakamega, Muranga and amongst women in central Kenya likely because our study covered largely a peri-urban and very rural population. $(11,23)$

Key factors associated with NHIF uptake in our study were increasing age up to age 69years, higher education level, higher income and higher health risk. Chances of having NHIF increased with age from 
age group 30-39, peaking at 60-69 then dropping likely due to loss of income. This is likely due to the fact that employment rates also increase in a similar manner and hence many of those with the cover are probably in formal employment. Indeed there was a positive association between income level and NHIF uptake with those earning less than Ksh.5000 being 3 times less likely to take up the cover than those earning above Ksh.10000. This is in keeping with previous studies that described a clear link between income level and health insurance uptake. $(11,27)$ Having formal education beyond secondary school was associated with a 2.34 higher chance of NHIF uptake than those who had only completed primary school. Indeed any education level below secondary school had no advantage given that those who did not complete primary school and those who never started any schooling were no different from those who completed primary school in terms of NHIF uptake.

The effects of education on health insurance uptake are in keeping with previous studies. $(11,27)$

Our findings confirm that people are more likely to take up health insurance once they have been diagnosed with a chronic illness and hence the findings of a 3 times higher likelihood of uptake for those with high health risk as compared to low risk. This is in keeping with other studies looking at voluntary health insurance enrollment that consistently show that perceived good health negatively affects uptake. $(27-29)$

However, one study from West Africa reported reduced willingness to pay in households that had experienced severe illness previously. This was attributed to possible negative experience with the health system which is known to reduce willingness to pay.

\section{Study Limitations}

This study did not explore in depth the actual knowledge of participants on NHIF and hence cannot conclusively delink knowledge with uptake.

Additionally, the study did not analyze for the effects of employment on NHIF uptake, yet this may be the mediator of the perceived association between education level and uptake.

An additional limitation is that this study did not include health system factors that may affect the perceptions and uptake of NHIF, yet these have been shown to markedly influence people's decisions on health insurance. Future studies should include this dimension.

\section{Conclusions}

The uptake of NHIF in rural western Kenya is very low, despite good levels of awareness and key factors associated with it are age, secondary school education, higher income status, and higher health risk. This calls for more contextualized strategies that address these factors in addressing universal coverage. Additionally, we recommend further mixed method studies that will describe the actual knowledge and perception of NHIF and assess effects of health system factors in NHIF uptake. 


\section{Abbreviations}

AMPATH- Academic Model Providing Access to Healthcare

AOR- Adjusted Odds Ratio

$\mathrm{CBHI}$ - Community based health insurance

CHMTs-County Health Management Teams

CU-Community Units

KPHC-Kenya Population and housing census

LMIC- Low- and middle-income-countries

MTRH-Moi Teaching and Referral Hospital

NACOSTI- National Commission for Science technology and Innovation

NCD-Non-Communicable Diseases

NHIF-National Hospital Insurance Fund

SHI- Socio Health Insurance

UHC- Universal Health Coverage

\section{Declarations}

\section{Acknowledgements}

This research was supported with funds from Access Accelerated and by cooperative agreement between World Bank and Ministry of Health Kenya NCDs Division. Implementation agreement between, Moi Teaching and Referral Hospital (MTRH) and Moi University and the Counties of Busia and Trans Nzoia where data collection occurred. The content is solely the responsibility of the authors and does not necessarily represent the official views of the $\mathrm{NIH}$ and CDC. AMPATH is acknowledged for their technical support in facilitating the study.

\section{Authors' Contributions}

JHK, GWM, AM, LL, KT, TA PI, GG, JK and WA contributed to the design, implementation, data collection, data analyses, and writing of the manuscript. WA, GG and JK contributed to critically refining the article. JHK, AM, LL, KT, TA and PI were involved in conducting the study. All authors read and approved the final manuscript. 


\section{Funding}

This work was supported by Access Accelerated and World Bank Grant Number: 0356 The funding body had no role in the design of the study; the collection, analysis, and interpretation of data; or the writing of the manuscript.

\section{Availability of data and materials}

The data sets used and/or analyzed during the current study can be made available by the corresponding author on reasonable request.

\section{Declarations}

\section{Authors' Information (optional)}

Not applicable

\section{Ethics approval and consent to participate}

The proposal was approved by the MTRH/Moi University Institutional Research and Ethics Committee (approval number 0002090), and National Commission for Science technology and Innovation (NACOSTI) (approval number NACOSTI/P/18/74238/24329) and the 4 County Health Management Teams (CHMTs). A written consent was obtained from all participants enrolled in the study who accepted to participate. Illiterate eligible women had their thumb prints taken and the process was witnessed by an independent adult. The IREC guidelines on confidentiality on research among vulnerable groups were followed. Data confidentiality was ensured by password protecting the computer.

\section{Consent for publication}

Not applicable

\section{Competing interests}

No competing interests to declare

\section{References}

1. Hsiao W, Berman P, Bazeyo. W. Is Social Health Insurance Feasible in Uganda? Uganda Heal Bull. 2001;

2. Carrin G, James C. Key performance indicators for the implementation of social health insurance. Applied Health Economics and Health Policy. 2005.

3. Knaul FM, Arreola-Ornelas H, Méndez-Carniado O, Bryson-Cahn C, Barofsky J, Maguire R, et al. Evidence is good for your health system: policy reform to remedy catastrophic and impoverishing health spending in Mexico. Lancet. 2006. 
4. Xu K, Evans DB, Kawabata K, Zeramdini R, Klavus J, Murray CJL. Household catastrophic health expenditure: A multicountry analysis. Lancet. 2003;

5. Obare V, Brolan CE, Hill PS. Indicators for Universal Health Coverage: can Kenya comply with the proposed post-2015 monitoring recommendations? Int J Equity Heal. 2014;123(13).

6. WHO. Health Systems Financing: The Path to Universal Coverage. World Health Report 2010. Reli Bosques excepcional Divers en los Andes Cent del Per. 2010;

7. Ekman B. Community-based health insurance in low-income countries: A systematic review of the evidence. Health Policy and Planning. 2004.

8. Yilma Z, Mebratie A, Sparrow R, Dekker M, Alemu G, Bedi AS. Health risk and insurance: Impact of ethiopia's community based health insurance on household economic welfare. World Bank Econ Rev. 2015;

9. Kenya National Bureau of Statistics (KNBS); ORC Macro. Economic Survey 2019. 2019.

10. Kenya National Bureau of Statistics. Economic survey 2020. Economic Survey 2020. 2020.

11. Kimani JK, Ettarh R, Warren C, Bellows B. Determinants of health insurance ownership among women in Kenya: Evidence from the 2008-09 Kenya demographic and health survey. International Journal for Equity in Health. 2014.

12. Informal Enterprises in Kenya. Informal Enterprises in Kenya. 2016.

13. Auger N, Alix C. . Income, Income distribution and Health in Canada. In: ) Social Determinants of Health 2nd Edition,. 2009. p. 61-75.

14. Preker AS, Carrin G, Dror D, Jakab M, Hsiao W, Arhin-Tenkorang D. Effectiveness of community health financing in meeting the cost of illness. Bulletin of the World Health Organization. 2002.

15. Kim J, Braun B, Williams AD. Understanding health insurance literacy: A literature review. Fam Consum Sci Res J. 2013;

16. Atun R, Aydin S, Chakraborty S, Sümer S, Aran M, Gürol I, et al. Universal health coverage in Turkey: Enhancement of equity. The Lancet. 2013.

17. Thornton RL, Hatt LE, Field EM, Islam M, Sols Diaz F, González MA. Social security health insurance for the informal sector in Nicaragua: A randomized evaluation. Health Economics. 2010.

18. Pia S, Diop F. Synopsis of Results on the Impact of Community-Based Health Insurance on Financial Accessibility to Health Care in Rwanda. In Partners for Health Reformplus (PHRplus) TE002.

Bethesda, MD: Abt Associates;

19. Ramesh B, Nishant J. Financial Performance of Private Sector Hospitals in India: Some Further Evidence. WP No 2006-4-8. 2006;

20. Oyekale AS. Factors influencing households' willingness to pay for National Health Insurance Scheme (NHIS) in Osun State, Nigeria. Stud Ethno-Medicine. 2012;

21. Boateng D, Awunyor-Vitor D. Health insurance in Ghana: Evaluation of policy holders' perceptions and factors influencing policy renewal in the Volta region. Int J Equity Health. 2013; 
22. Cerceau S. Gender equality in access to health care: The role of social health protection: A case study on India's national health insurance scheme RSBY. GIZ Discussion Papers on Social Protection. 2012.

23. Sundays ME, K NJ, C M. Determinants of Uptake and Utilization of National Hospital Insurance Fund Medical Cover by People in the Informal Sector in Kakamega County, Kenya. Univers J Public Heal. 2015;

24. KNBS. 2019 Kenya Population and Housing Census Volume 1: Population by County and SubCounty. 2019 Kenya Population and Housing Census. 2019.

25. Kazungu JS, Barasa EW. Examining levels, distribution and correlates of health insurance coverage in Kenya. Trop Med Int Heal. 2017;

26. Social Health Insurance for Developing Nations. Social Health Insurance for Developing Nations. 2007.

27. Otieno PO, Wambiya EOA, Mohamed SF, Donfouet HPP, Mutua MK. Prevalence and factors associated with health insurance coverage in resource-poor urban settings in nairobi, Kenya: A crosssectional study. BMJ Open. 2019;

28. David Mark D, Radermacher R, Koren R. Willingness to pay for health insurance among rural and poor persons: Field evidence from seven micro health insurance units in India. Health Policy (New York). 2007;

29. Xu W, Cai GJ, Li GN, Cao JJ, Shi QH, Bai J. Age or health status: Which influences medical insurance enrollment greater? J Glob Health. 2016; 